\title{
Optimization design of marine seawater desulfurization technology
}

\author{
Junfu Yuan ${ }^{1, *}$, and Meizhou $\mathrm{Xu}^{2}$ \\ ${ }^{1}$ Jiangsu Maritime Institute, 309 Gezhi Road, Jiangning District, Nanjing, Jiangsu, China \\ ${ }^{2}$ Jiangsu Maritime Bureau, 238 Nanjing Central Road Gulou,District, Nanjing, Jiangsu, China
}

\begin{abstract}
Because ships burn inferior fuel, the emission of ship exhaust gas has a great impact on the environment. In order to effectively deal with the increasingly strict limit of sulfur content and $\mathrm{SO}_{2}$ emission of ship fuel by the International Maritime Organization. On the basis of analyzing the characteristics of $\mathrm{SO}_{2}$ gas soluble in seawater, this paper studies and compares the current industrial seawater desulphurization technology and other flue gas desulfurization technologies, puts forward the feasibility of the application of seawater desulphurization technology in the exhaust gas emission of marine diesel engine, and theoretically designs and calculates seawater desulphurization technology is pointed out.
\end{abstract}

\section{Introduction}

In world cargo transport, Ocean transportation is favored because of its advantages of large volume, safety and economy, The number of marine vessels has increased rapidly, In turn, it brings serious air pollution and marine pollution. Because marine diesel engines usually burn heavy oil of inferior quality, It releases a tail gas with complex contaminants, $\mathrm{NO}_{\mathrm{X}}, \mathrm{SO}_{\mathrm{X}}, \mathrm{CO}, \mathrm{HC}$ and $\mathrm{PM}$, These pollutants are mainly $\mathrm{NO}_{\mathrm{X}}$ and $\mathrm{SO}_{\mathrm{X}}$, Also, they are International Maritime Organization, by the International Maritime Organization Abbreviations: IMO) as the primary control of ship exhaust pollutants. The $\mathrm{NO}_{\mathrm{X}}$ in tail gas mainly include $\mathrm{NO}, \mathrm{NO}_{2}, \mathrm{~N}_{2} \mathrm{O}, \mathrm{N}_{2} \mathrm{O}_{5}$, Among them $\mathrm{NO}$ account for more than $90 \%$. NO readily oxidizes to $\mathrm{NO}_{2}$, in air It can poison the heart and lungs of the human body. $\mathrm{SO}_{2}$, in $95 \%$ of $\mathrm{SO}_{\mathrm{X}} \mathrm{SO}_{3}$ only $5 \% . \mathrm{SO}_{2}$ direct damage to human health, Is also the main cause of acid rain, Seriously affecting the environment, It is imperative to take corresponding technical measures to limit the emission of sulfur oxides.

\section{Application and development of seawater desulfurization technology}

\subsection{Comparison of various flue gas desulfurization techniques}

\footnotetext{
*Corresponding author: yujufu@163.com
} 
Desulfurization of sulfur-containing flue gas is one of the important ways to control $\mathrm{SO}_{2}$ air pollution. At present, there are many flue gas desulfurization methods used in industry, which can be divided into dry method, semi-dry method and wet method according to the form of desulfurizer. however, the application of various flue gas desulfurization technologies has remained in the industry of fixed pollution sources, but in the ships with mobile pollution sources, the researchers of one country have paid less attention to it, on the other hand, because the existing desulfurization process is limited to conditions. It is not fully applicable to ships. Therefore, the exhaust desulfurization of marine diesel engine has not been formed in China or abroad.

\subsection{Development of seawater desulfurization technology and the feasibility of ship application}

In many flue gas desulfurization technologies, seawater flue gas desulfurization technology has simple and reliable technology and high desulfurization efficiency (Table 1), and its research and application in industry have developed rapidly and gradually tends to mature .Since the $1980 \mathrm{~s}$, nearly 100 sets of seawater desulfurization equipment have been built worldwide for the operation of coastal thermal power plants .ABB is leading the world in seawater desulfurization, using almost all of its domestic flue gas desulfurization .In addition, environmental protection companies in Europe and America and have fully developed and studied seawater flue gas desulfurization technology .

$\mathrm{SO}_{2}$ is a colorless, toxic gas with a strong irritating odor and is soluble in water. the solubility of $\mathrm{SO}_{2}$ in water at different temperatures $\left(20 \sim 50^{\circ} \mathrm{C}\right)$ is shown in figure 1 .

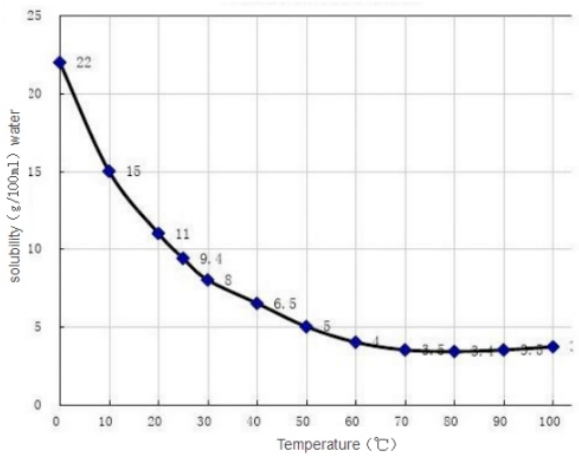

Fig. 1. Solubility of the $\mathrm{SO}_{2}$ in water at different temperatures.

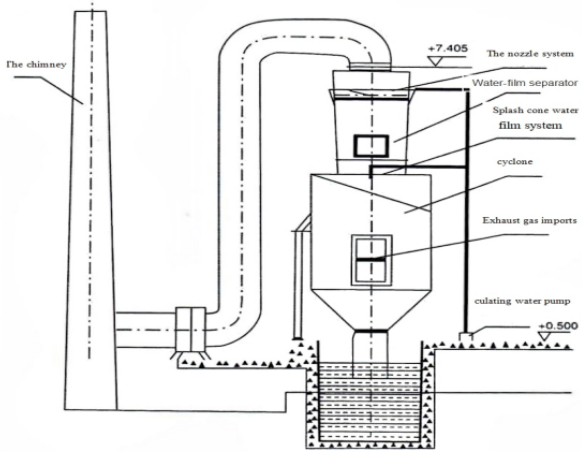

Fig. 2.Structure diagram of desulfurization tower.

Fig .1, the solubility of $\mathrm{SO}_{2}$ gas in water increases with the decrease of temperature under certain concentration and pressure. GhaziAl-Enezi, Hisham Ettouney et al. conducted $\mathrm{SO}_{2}$ gas absorption experiments using seawater of different salinity in the laboratory. the experimental results show that the solubility of $\mathrm{SO}_{2}$ gas in seawater is larger than that in pure water. in a certain range, the lower the temperature, the greater the salt content in water, the more favorable the dissolution and absorption of $\mathrm{SO}_{2}$ gas.

\section{Design of flue gas desulfurization process for marine seawater}

Fig .3 is a sulfur-containing waste gas desulfurization process of marine diesel engine designed by referring to the current industrial seawater flue gas desulfurization process principle. Diesel flue gas passes through the dust collector and heat exchanger into the bottom of the desulfurization tower, Design of seawater cooling unit is beneficial to 
dissolve and absorb $\mathrm{SO}_{2}$ in flue gas, Improve desulfurization efficiency. The sulfur-containing flue gas is fully mixed from the bottom of the desulfurization tower up to the top-down multi-layer spray seawater countercurrent, $\mathrm{SO}_{2}$ was sucked out by spray water, Flue gas up through the mist remover to achieve desulphurization emissions, A mist remover is installed on the upper part of the desulfurization tower to remove the $\mathrm{SO}_{2}$. contained in the water mist in the flue gas desulfurization tower effluent due to dissolution, absorption of $\mathrm{SO}_{2}$ after a series of physical and chemical reactions, Production of a large number of $\mathrm{HSO}_{3}-$ and $\mathrm{SO}_{3}{ }^{2-}$, The $\mathrm{PH}$ value decreased to 2.7 3.5.

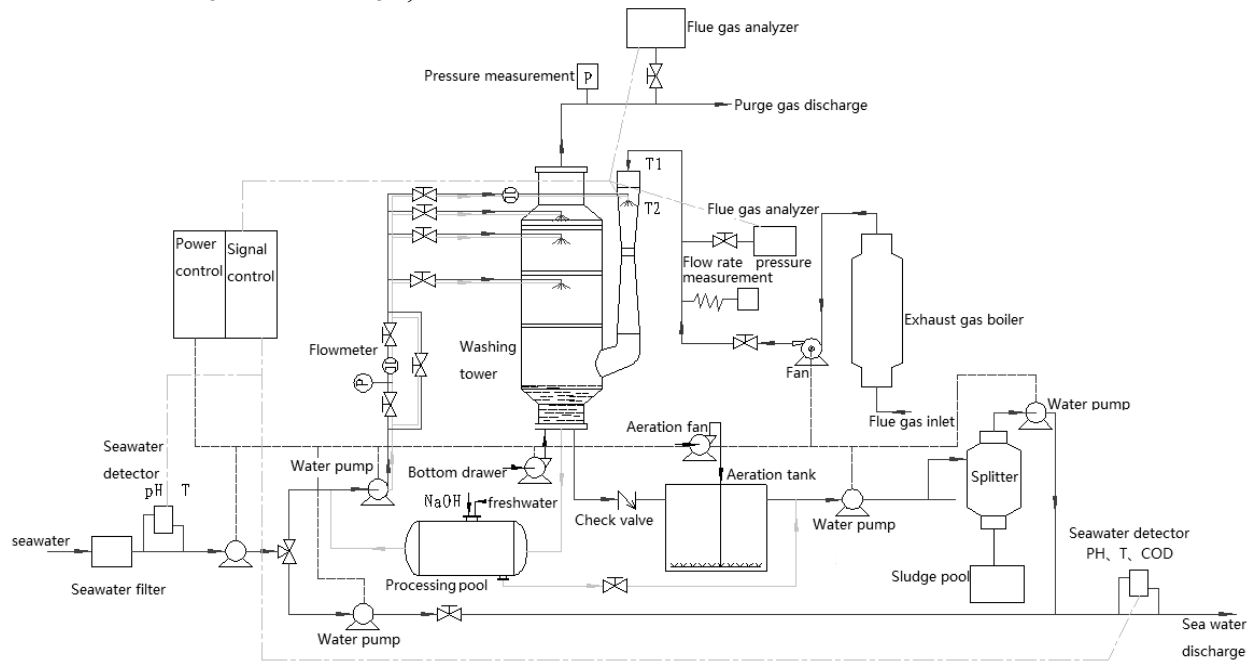

Fig. 3. Flowchart of desulfurization process for marine seawater.

\section{Key technologies for the process}

\subsection{Seawater treatment after desulphurization}

The neutralization tank and aeration tank are designed in this process. considering that the onboard plant has much smaller capacity than that of the terrestrial power plant, in order to simplify the seawater system and save power, this design adopts a common seawater system with the sprayed seawater (figure 2; fresh seawater is divided into two ways) to neutralize the delithiated seawater.

The size of the neutral tank and the a eration tank is mainly determined according to the power size of the diesel engine and the fuel sulfur content, and the calculation formula is: $\mathrm{V}=\mathrm{K} \mathrm{P} \mathrm{C}$ (1) The $\mathrm{K}$ is the coefficient; according to the ship size 7.5 9.5, the $\mathrm{P}$ is the diesel engine power $\mathrm{kw}$, the $\mathrm{C}$ is fuel sulfur content; the weight percentage.

According to formula (1) ; 3000 3000 kw diesel engine , 2.5\% sulfur fuel , $20 \sim 50 \mathrm{~m}$ ${ }^{3}$.In order to reduce the cost of ship building or renovation, and save space and space, the neutral pool and a eration tank can be converted from the hull top cabinet .

\subsection{Re-cooling of flue seawater}

Desulfurization tower is the core component in seawater desulphurization process. Whether the selection of desulfurization tower, inner part of tower and auxiliary equipment is reasonable and reliable is the key of process design. In the marine flue gas desulfurization 
process, the influence on the exhaust resistance of diesel engine should be considered, and the arrangement form of the desulfurization tower and the inner parts of the tower with small running resistance and convenient operation should be selected. At present, in the industrial seawater desulfurization process, more desulfurization tower type has spray absorption empty tower, tray tower, liquid column tower, jet bubbling tower and so on.

\subsection{Selection of desulfurization tower}

In the desulfurization tower, the cost - effective flue gas flow rate is $2.2 \sim 3.0 \mathrm{~m} / \mathrm{s}$. Through test and calculation, the flue gas flow speed in the diesel exhaust pipe of modern large and medium - sized ships usually decreases at $10 \sim 15 \mathrm{~m} / \mathrm{s}$, when the exhaust pipe enters the tower, which makes the sectional area of the tower is $4 \sim 6$ times the area of that of the smoke exhaust pipe. After calculation, the inner diameter of the desulfurization tower is designed as $2 \sim 2.5$ times the inner diameter of the exhaust pipe of the diesel machine. The desulfurization tower can be designed to be installed in the ship chimney to reduce the impact on the cabin environment .

\subsection{Selection of nozzles}

The axial nozzle (Figure 4) was chosen for this design solution for the reason that the axial nozzle produces a solid conical jet form, the effect of which is shown in (Figure 5). Compared with the tangential nozzle its advantages are; produce the same size droplets when the pressure drop is small, at the same pressure drop, the size of its droplets smaller. Compared with the spiral nozzle its advantages are; simple structure, cheap, not easy to damage, easy to manage. It is suitable for use in low flow environments on board.
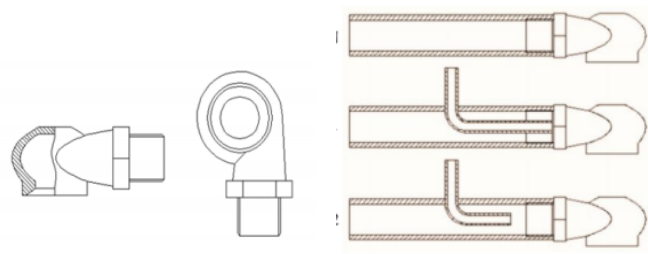

Fig. 4. Schematic diagram of axial nozzle structure.

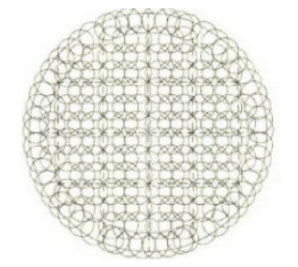

Fig. 5. Effect of spray atomization of axial nozzle.

\subsection{Main factors affecting desulfurization efficiency}

The main factors affecting the desulfurization efficiency of the process flow are : flue gas temperature (Fig . 6), sulfur content in the fuel (Fig . 7), sea water temperature (Fig . 8), and concentration and change of desulfurization efficiency under different working conditions with flow (Fig. 9), etc . 


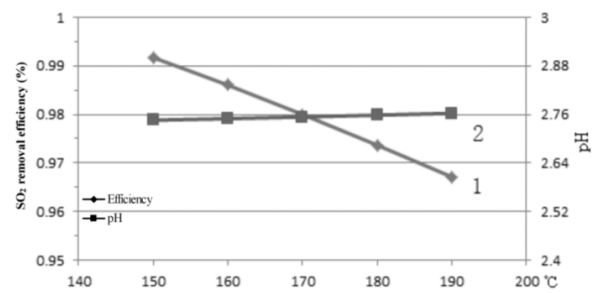

Fig. 6. Effect of flue gas temperature on desulfurization efficiency.

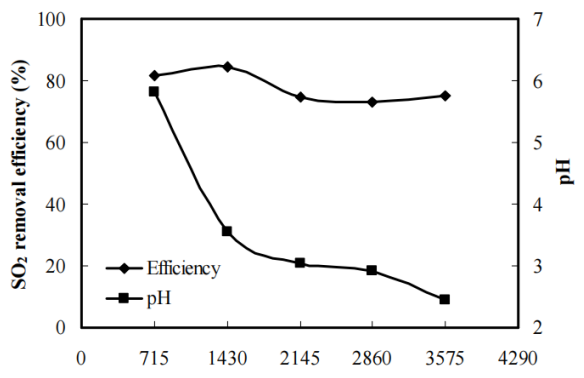

Fig. 7. Effect of the sulfur content in the fuel oil on the desulfurization efficiency.

The analysis is from Fig .6 9; under the normal operation condition of the diesel engine, if the flue gas temperature is cooled to about $160^{\circ} \mathrm{C}$, the sulfur content of the fuel is controlled below $3.2 \%$, the seawater temperature is kept below $25{ }^{\circ} \mathrm{C}$, and the desulfurization efficiency of the unit can reach $99 \%$ theoretically.

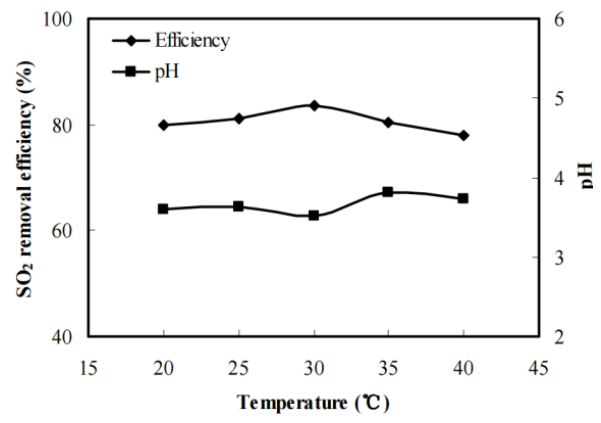

Fig. 8. Effect of seawater temperature on desulfurization efficiency.

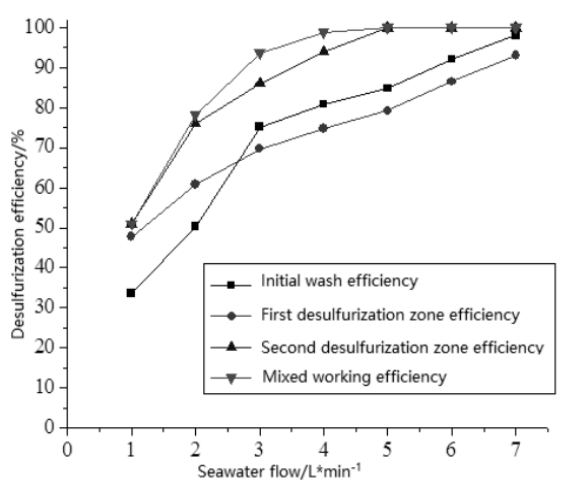

Fig. 9. Concentration and desulfurization efficiency changing of different work ways along with flow changes.

\section{Conclusion}

In the context of global energy conservation and emission reduction, ship desulfurization system has received extensive attention in order to cope with increasingly stringent emission regulations. The research and development of comprehensive treatment system for waste gas and multi-pollutants is the trend of the times. In this paper, it is pointed out that seawater desulfurization technology is suitable for specific conditions of ship navigation. The equipment is relatively simple and reliable, the cost of investment and maintenance is low, the desulfurization efficiency is high, and there is no by-product and secondary pollution. It can be predicted that in the near future large ocean container ships and bulk carriers will install marine desulfurization system, and the harmful substances in ship exhaust gas will be effectively controlled.

This work was financially supported by Natural Science Research Project of Higher Education in Jiangsu Province (20KJB580008). 


\section{References}

1. Long Nguyen Van Duc,Lee Dong Young,Jin Kim Myung,Choongyong Kwag,Mok Lee Young,Won Lee Sung,Lee Moonyong. Advanced and Intensified Seawater Flue Gas Desulfurization Processes: Recent Developments and Improvements[J]. Energies,2020,13(22).

2. Leng, Cui Jinquan, Zhao Chao, Liu Guochen, Wang Tingyong. Simulation and Optimization of Marine Flue Gas Seawater Desulfurization Process [J].] for Ships Modern Chemical Industry 40(S1):296-299.(in Chinese)

3. Fan Hongshuai. Numerical Simulation [D].] of Flue Gas Desulfurization Spray Tower in Ship Harbin University of Engineering .(in Chinese)

4. Chen Zhangyue. Desulfurization Technology of Marine Diesel Engine Exhaust Gas J]. China Water Transport (Second Half Month),2013,13(11):202-203 205.(in Chinese) 